\title{
BMJ Open Influence of prior comorbidities and chronic medications use on the risk of COVID-19 in adults: a population-based cohort study in Tarragona, Spain
}

\author{
Angel Vila-Córcoles, ${ }^{1,2}$ Olga Ochoa-Gondar, ${ }^{1,2}$ Eva M. Satué-Gracia (D) , ${ }^{1,2}$ \\ Cristina Torrente-Fraga, ${ }^{3}$ Frederic Gomez-Bertomeu, ${ }^{4}$ Angel Vila-Rovira, ${ }^{2}$ \\ Immaculada Hospital-Guardiola, ${ }^{1}$ Cinta de Diego-Cabanes, ${ }^{1}$ \\ Ferran Bejarano-Romero, ${ }^{5}$ Josep Basora-Gallisà ${ }^{6}$
}

To cite: Vila-Córcoles A, Ochoa-Gondar 0, SatuéGracia EM, et al. Influence of prior comorbidities and chronic medications use on the risk of COVID-19 in adults: a population-based cohort study in Tarragona, Spain. BMJ Open 2020;10:e041577. doi:10.1136/ bmjopen-2020-041577

- Prepublication history and additional material for this paper is available online. To view these files, please visit the journal online (http://dx.doi.org/10. 1136/bmjopen-2020-041577).

Received 16 June 2020 Revised 16 November 2020 Accepted 17 November 2020

Check for updates

(C) Author(s) (or their employer(s)) 2020. Re-use permitted under CC BY-NC. No commercial re-use. See rights and permissions. Published by BMJ.

For numbered affiliations see end of article.

Correspondence to Dr Eva M. Satué-Gracia; esatue.tgn.ics@gencat.cat

\section{ABSTRACT}

Objective To investigate possible relationships between pre-existing medical conditions (including common comorbidities and chronic medications) and risk for suffering COVID-19 disease in middle-aged and older adults.

Design Population-based retrospective cohort study. Setting Twelve primary care centres (PCCs) in Tarragona (Spain).

Participants 79083 people (77676 community-dwelling and 1407 nursing-home residents), who were all individuals aged $>50$ years affiliated to the 12 participating PCCs.

Outcomes Baseline cohort characteristics (age, sex, vaccinations, comorbidities and chronic medications) were established at study start (1st. March 2020) and primary outcome was time to COVID-19 confirmed by PCR among cohort members throughout the epidemic period (from 1st. March 2020 to 23rd. May 2020). Risk for suffering COVID-19 was evaluated by Cox regression, estimating multivariable HRs adjusted for age, sex, comorbidities and medications use.

Results During the study period, 2324 cohort members were PCR-tested, with 1944 negative and 380 positive results, which means an incidence of 480.5 PCRconfirmed COVID-19 cases per 100000 persons-period. Assessing the total study cohort, only age (HR 1.02; $95 \% \mathrm{Cl} 1.01$ to $1.03 ; \mathrm{p}=0.002$ ), nursing-home residence (HR 21.83; 95\% Cl 16.66 to $28.61 ; p<0.001$ ) and receiving diuretics ( $\mathrm{HR} 1.35 ; 95 \% \mathrm{Cl} 1.04$ to $1.76 ; \mathrm{p}=0.026$ ) appeared independently associated with increased risk. Smoking (HR 0.62; 95\% Cl 0.41 to 0.93; $p=0.022$ ), ACE inhibitors (HR 0.68; $95 \% \mathrm{Cl} 0.47$ to $0.99 ; \mathrm{p}=0.046$ ) and antihistamine (HR $0.47 ; 95 \% \mathrm{Cl} 0.22$ to $1.01 ; p=0.052$ ) were associated with a lower risk. Among communitydwelling individuals, cancer (HR 1.52; 95\% Cl 1.03 to $2.24 ; p=0.035$ ), chronic respiratory disease (HR 1.82; $95 \% \mathrm{Cl} 1.08$ to $3.07 ; p=0.025)$ and cardiac disease (HR 1.53; $95 \% \mathrm{Cl} 1.06$ to $2.19 ; \mathrm{p}=0.021$ ) emerged to be also associated with an increased risk. Receiving ACE inhibitors (HR 0.66; 95\% $\mathrm{Cl} 0.44$ to $0.99 ; \mathrm{p}=0.046$ ) and influenza vaccination ( $\mathrm{HR} 0.63 ; 95 \% \mathrm{Cl} 0.44$ to $0.91 ; \mathrm{p}=0.012$ ) was associated with decreased risk.
Strengths and limitations of this study

- This is a population-based cohort study involving 79083 adults aged $\geq 50$ years in Tarragona (Southern Catalonia, Spain).

- Cohort members were retrospectively followed up across the first wave of COVID-19 epidemic period from 1st. March 2020 to 23rd. May 2020.

- Relationships between PCR-confirmed COVID-19 incidence and chronic comorbidities and chronic medications use were assessed by multivariable Cox regression models.

- Despite the large size of study cohort, the number of events was relatively low, which limits statistical power (especially in subgroup analyses).

- PCR testing was not routinely performed (prioritised for patients with severe case), and asymptomatic/ oligosymtomatic cases were underestimated.

Conclusion Age, nursing-home residence and multiple comorbidities appear predisposing for COVID-19.

Conversely, receiving ACE inhibitors, antihistamine and influenza vaccination could be protective, which should be closely investigated in further studies specifically focused on these concerns.

\section{INTRODUCTIONN}

Currently, population-based clinical data on the SARS-CoV-2 coronavirus (COVID-19 disease) pandemic are limited. Furthermore, the available clinical information comes mainly from hospitalised and therefore more severe patients (especially those who required intensive care or those who died $)^{1-4}$ and there are few community data, from primary care, covering a larger sample of the population. In fact, there is very scarce data assessing incidence and risk for suffering infection in relation to the pre-existing clinical characteristics of the population (ie, baseline risk profile 
according to previous underlying conditions/medications use) ${ }^{56}$

Earlier studies regarding clinical characteristics and prevalence of comorbidities in patients infected with SARS-CoV-2 reported that diabetes mellitus, obesity, cardiovascular disease (including hypertension), chronic respiratory diseases and smoking were major risk factors associated with severe COVID-19. ${ }^{1-4}$

A more recent systematic review and meta-analysis has reported that COVID-19 patients with cardiovascular disease, hypertension, diabetes, congestive heart failure, chronic kidney disease and cancer have a greater risk of mortality compared with patients with COVID-19 without these comorbidities. ${ }^{7}$ However, these results (mainly based on hospitalised cases and observational data) were likely to be confounded by age or other conditions (including sociodemographic) and therefore concerns have been raised about the possibility that some of these comorbidities/underlying conditions increase the risk for severe disease, but they were not really related 'per se' to an increased risk of infection.

Unlike most previous studies that examined risk factors for poor prognosis, few published studies have reported characteristics associated with susceptibility to SARS-CoV-2 infection. On this, recently published primary care cohort study from the Oxford Royal College of General Practitioners in the UK has reported similar risk factors associated with positive PCR testing as observed for severe outcomes of COVID-19 in hospital settings (except for smoking) and has provided some evidence of potential sociodemographic factors associated with a positive PCR testing (including socioeconomic deprivation, population density and ethnicity). ${ }^{5}$

Considering the relationship between sociodemographic aspects and susceptibility for COVID-19, some studies reported that male sex and older age are associated with a higher risk of infection and a worse prognosis. However, evidence on sociodemographic and clinical disparities related to the susceptibility for SARS-COV-2 infection is limited and new studies collecting these data are needed. ${ }^{568}$

Taking this situation into account, we designed this study whose objective was to investigate the incidence and risk of suffering from COVID-19 infection in adults over 50 years in Tarragona (Southern Catalonia, Spain) with pre-existing comorbidities or using chronic medications, over the first 12 weeks' pandemic period in the study area.

\section{METHODS}

\section{Design, setting and study population}

This is a retrospective cohort study involving 79083 people aged $\geq 50$ years old in the region of Tarragona (a residential-industrial urban area in Southern Catalonia, Spain, with an overall population of 210672 all-age inhabitants). The cohort consisted of individuals $>=50$ years old date of birth before 1st. January 1970) affiliated in the 12 participating primary care centres (PCCs) managed by

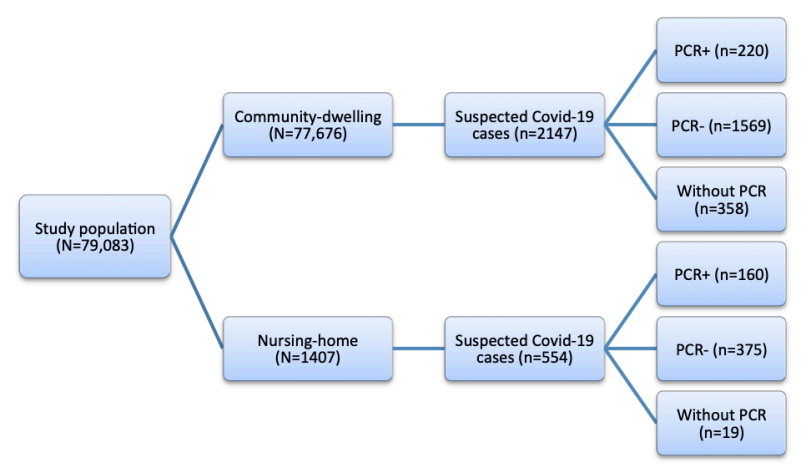

Figure 1 Flow diagram of the study.

the Institut Català de la Salut (ICS) in the study area. In the study setting (concretely ‘Tarragonés', 'Alt Camp' and 'Conca de Barberà' counties), there are 16 PCCs overall. Of them, 12 PCCs (those included in this study) are managed by the ICS, whereas the remaining 4 PCCs are managed by other providers and were not included in the present study. The study cohort represents approximately $75 \%$ of overall inhabitants aged 50 years or older in the study area according to census data. ${ }^{9}$ Reference laboratory and hospital for the 12 participating PCCs were the Hospital Universitari Joan XXIII and its Microbiological Service in Tarragona city.

Figure 1 shows the distribution of the cohort members between nursing-home residents and community dwellings; and also the number of suspected cases and the PCR tests (positive and negative) performed in the aforementioned population subgroups.

Cohort members were retrospectively followed up from 1st. March 2020 (the beginning of the epidemic period in the region) until the occurrence of any study event (COVID-19 diagnosis) or until the end of the 12-week follow-up (23 May 2020). The study was approved by the ethical committee of the Institution (Ethics Committee IDIAP Jordi Gol, Barcelona, file 20/065-PCV) and was conducted according to the Helsinki Declaration and Spanish legislation on biomedical studies, data protection and respect for human rights. ${ }^{10}$

\section{Data sources}

The CAPAMIS Research Database, a pre-existing institutional database that we had previously used for other cohort studies carried out in our region, ${ }^{11}$ was rapidly updated to become the primary data source for this epidemiological study. Briefly, this research database collects information from the electronic clinical records system (in operation since the 2000s) which is used, at the institutional level, by the PCCs in the region. It includes administrative and clinical data, such as diagnoses, coded according to the International Classification of Diseases 10th Revision (ICD-10) and it allowed us to identify sociodemographic characteristics, comorbidities, history of vaccinations and use of active drugs among cohort members to establish their baseline characteristics at the beginning of the study period (March 1, 2020). 
At the start of the COVID-19 pandemic in our region, two new alerts related to laboratory records (results of diagnostic tests for SARS-CoV-2 infection) and ICD-10 codes for COVID-19 suspicion (B34.2: Unspecified coronavirus infection; B97.29: Other coronavirus as the cause of diseases classified elsewhere) were added to the electronic clinical records system. The registries provided from both data sources were linked to build an anonymised research database, which is the one we have used for this study.

\section{Outcomes}

Primary outcome was time (from study start) to COVID-19 confirmed by positive Polymerase Chain Reaction (PCR) test among cohort members throughout the study period (from March 1, 2020 to May 23, 2020). We also reported, in the descriptive analysis, cases with a negative result in the PCR test (laboratory-excluded cases) and cases of presumed COVID-19 (people who were assigned a code of clinical suspicion of the disease but no PCR test was performed).

The guidelines of the Department of Health of the Generalitat de Catalunya were followed for the laboratory diagnosis of COVID-19 by reverse transcription PCR (RTPCR). ${ }^{12}$ In summary, the Cobas SARS-CoV-2 RT-PCR technique with European Conformity and Food and Drug Administration (CE-FDA) marking was performed from samples collected by nasal and pharyngeal swabs with transport medium for viruses and refrigerated at $4^{\circ} \mathrm{C}$ for a maximum of 48 hours; sensitivity and specificity close to $100 \%$ have been reported for this test. ${ }^{13}$ When the epidemic period began, there was little availability of PCR tests, and they were prioritised for severe cases (requiring hospital admission) and for nursing-home residents (since there were several outbreaks in nursing homes), while among suspected cases of outpatient management, fewer PCR tests were conducted.

\section{Exposure}

Baseline use of common chronic medications, which could be hypothetically related to the physiopathological mechanism of SARS-CoV-2 infection or virulence (eg, antihypertensive, antiplatelet/anticoagulant and/ or anti-inflammatory drugs), were considered as main explanatory variables possibly related to the occurrence of COVID-19 for the present study. It was determined by a review of the PCCs' electronic clinical records system that contains specially designated fields for medications prescribed. Thus, active medication treatments in each cohort member on 1 March 2020, coded according to the Anatomical, Therapeutic, and Chemical classification system (ATC) of the $\mathrm{WHO},{ }^{14}$ were identified from the patient treatment plan registered in the PCC's clinical records system, and included the following therapeutic groups: antihypertensive (diuretics, beta-blockers, ACE inhibitors (ACEIs), angiotensin II receptor blockers (ARBs), calcium channel blockers, statins, anticoagulants (warfarin and new oral anticoagulant drugs), antiplatelet drugs, antidiabetic drugs (insulin, oral antidiabetic drugs), inhaled respiratory drugs, antineoplastic agents, systemic corticosteroids, non-steroidal anti-inflammatory drugs (NSAIDs), chloroquine/hydroxychloroquine, antihistamines, proton-pump inhibitors and benzodiazepines (see online supplemental appendix).

\section{Covariates}

Besides age, sex, residence (community-dwelling/ nursing-home) and vaccinations' history (influenza vaccination in prior autumn or pneumococcal vaccination at any time), the following comorbidities/underlying conditions, obtained from the registries in the electronic PCCs clinical records on 1 March 2020, were considered: neurological disease (including dementia and stroke), cancer (solid organ or haematological neoplasia diagnosed in the past 5 years), chronic renal failure, systemic autoimmune rheumatic diseases (including rheumatoid arthritis and lupus), chronic respiratory disease (including chronic bronchitis/emphysema and/or asthma), chronic heart disease (including congestive heart failure, coronary artery disease and other cardiopathies), atrial fibrillation, chronic liver disease (including chronic hepatitis and cirrhosis), hypertension, diabetes mellitus, hypercholesterolaemia, obesity and smoking (see online supplemental appendix). Comorbidities were chosen on the basis of immunocompromise degree and risk for severe respiratory illness as usually used in other studies about community-acquired pneumonia. ${ }^{11}$

\section{Statistical analyses}

We calculated the incidence rates (IRs), with their corresponding 95\% confidence intervals (CIs)—estimated assuming a Poisson distribution for uncommon eventsfor PCR-confirmed COVID-19 per 100000 person-period (12 weeks). The baseline characteristics of the individuals, based on whether or not they had COVID-19, were compared using $\chi^{2}$ or Fisher's test as appropriate, in bivariate analyses.

Cox regression analyses were used to calculate unadjusted and multivariable-adjusted hazard ratios (HRs) to estimate the association between baseline exposure conditions and the time to PCR-confirmed COVID-19 diagnosis among cohort members throughout the epidemic period (from March 1, 2020 to May 23, 2020). The multivariable Cox models were made with all abovementioned exposure variables and covariables (ie, age, sex, residence, vaccinations history, comorbidities/underlying conditions and medications use). The method to select a subset of covariables to include in the final model was the purposeful selection. The final models include significant, confounders and all covariables judged clinically or epidemiologically relevant. A main analysis was performed for the entire study cohort $(\mathrm{N}=79083)$ as well as two subgroup analyses for community-dwelling individuals $(n=77676)$ and for nursing-home residents $(n=1407)$. The level of statistical significance was established at 
Table 1 Incidence of PCR-confirmed COVID-19 cases according to baseline demographic and clinical characteristics (comorbidities/medications) in the total study cohort ( $\mathrm{N}=79083$ ): Tarragona region (Southern Catalonia, Spain), March 1, 2020- May23, 2020

\begin{tabular}{|c|c|c|c|}
\hline \multirow[b]{2}{*}{ Characteristic } & \multirow{2}{*}{$\begin{array}{l}\text { Study population } \\
\text { (N=79083) } \\
\mathrm{n}(\%)\end{array}$} & \multicolumn{2}{|c|}{ PCR-confirmed COVID-19 cases $(n=380)$} \\
\hline & & $\begin{array}{l}\text { Univariate analysis } \\
\mathrm{n}(\%) \mathrm{p} \text { value }\end{array}$ & Incidence rate \\
\hline \multicolumn{4}{|l|}{ Sociodemographic } \\
\hline \multicolumn{4}{|l|}{ Age } \\
\hline 50-64 years & $42684(54.0)$ & $101(26.6)<0.001$ & $236.6(193.6-288.7)$ \\
\hline $65-79$ years & $26013(32.9)$ & $95(25.0)$ & $365.2(295.4-452.9)$ \\
\hline$\geq 80$ years & $10386(13.1)$ & $184(48.4)$ & $1771.6(1527.1-2055.1)$ \\
\hline \multicolumn{4}{|l|}{ Sex } \\
\hline Men & $37626(47.6)$ & 158 (41.6) 0.019 & $419.9(358.6-491.7)$ \\
\hline Women & $41457(52.4)$ & $222(58.4)$ & $535.5(464.8-616.4)$ \\
\hline Community-dwelling & $77676(98.2)$ & $220(57.9)<0.001$ & $283.2(245.8-326.0)$ \\
\hline Nursing-home residence & $1407(1.8)$ & $160(42.1)$ & $11371.7(9711.4-13316.3)$ \\
\hline \multicolumn{4}{|l|}{ Comorbidities } \\
\hline Neurological disease & $2317(2.9)$ & $66(17.4)<0.001$ & $2848.5(2236.1-3617.6)$ \\
\hline Renal disease & $4476(5.7)$ & $49(12.9)<0.001$ & $1094.7(812.3-1445.0)$ \\
\hline Cancer & $6630(8.4)$ & 49 (12.9) 0.001 & $739.1(548.4-975.6)$ \\
\hline Rheumatic disease & $872(1.1)$ & $2(0.5) 0.281$ & $229.4(27.8-828.0)$ \\
\hline Respiratory disease & $7272(9.2)$ & $63(16.6)<0.001$ & $866.3(667.1-1126.2)$ \\
\hline Cardiac disease & $13435(17.0)$ & $123(32.4)<0.001$ & 915.5 (762.6-1098.6) \\
\hline Atrial fibrillation & $3786(4.8)$ & $55(14.5)<0.001$ & 1452.7 (1077.9-1917.6) \\
\hline Liver disease & $1465(1.9)$ & $8(2.1) 0.714$ & 546.1 (235.4-1075.8) \\
\hline Diabetes & $13317(16.8)$ & $102(26.8)<0.001$ & 765.9 (626.5-934.4) \\
\hline Hypertension & $34945(44.2)$ & $223(58.7)<0.001$ & $638.1(553.9-734.5)$ \\
\hline Hypercholesterolaemia & $27314(34.5)$ & 133 (35.0) 0.850 & $486.9(411.0-576.5)$ \\
\hline Obesity & $21678(27.4)$ & 96 (25.3) 0.347 & $442.8(362.2-540.3)$ \\
\hline Smoking & $12750(16.1)$ & $27(7.1)<0.001$ & 211.8 (139.6-309.2) \\
\hline \multicolumn{4}{|l|}{ Chronic medications use } \\
\hline Diuretics & $8481(10.7)$ & $111(29.2)<0.001$ & $1308.8(1090.2-1570.6)$ \\
\hline Beta-blockers & 9571 (12.1) & 68 (17.9) 0.001 & 710.5 (557.7-902.3) \\
\hline ACEls & $16419(20.8)$ & $92(24.2) 0.097$ & $560.3(453.3-694.8)$ \\
\hline ARBs & 8869 (11.2) & 39 (10.3) 0.556 & $439.7(314.0-598.0)$ \\
\hline Calcium channel blockers & $6490(8.2)$ & $52(13.7)<0.001$ & $801.2(594.5-1057.6)$ \\
\hline Statins & $16134(20.4)$ & 69 (18.2) 0.277 & $427.7(335.7-543.1)$ \\
\hline Oral anticoagulants & $3912(4.9)$ & $46(12.1)<0.001$ & $1175.9(857.2-1575.7)$ \\
\hline Antiplatelet drugs & 9154 (11.6) & $86(22.6)<0.001$ & 939.5 (760.0-1165.0) \\
\hline Insulin & $3042(3.8)$ & $39(10.3)<0.001$ & $1282.1(915.4-1743.6)$ \\
\hline Oral antidiabetic drugs & $10585(13.4)$ & 69 (18.2) 0.006 & 651.9 (511.7-827.9) \\
\hline Inhaled respiratory drugs & $6293(8.0)$ & $61(16.1)<0.001$ & $969.3(746.4-1260.1)$ \\
\hline Antineoplastic agents & $1614(2.0)$ & $8(2.1) 0.929$ & 495.7 (213.6-976.5) \\
\hline Systemic corticosteroids & $1252(1.6)$ & $5(1.3) 0.676$ & 399.4 (129.4-930.5) \\
\hline NSAIDs & $4321(5.5)$ & $12(3.2) 0.047$ & 277.7 (143.6-486.0) \\
\hline Chloroquine & $168(0.2)$ & $0(0.0) 0.367$ & $0(-)$ \\
\hline Antihistamines & $3264(4.1)$ & $7(1.8) 0.025$ & 214.5 (86.0-446.1) \\
\hline Proton-pump inhibitors & $17931(22.7)$ & $142(37.4)<0.001$ & 791.9 (668.4-937.6) \\
\hline
\end{tabular}




\begin{tabular}{|c|c|c|c|}
\hline \multirow[b]{2}{*}{ Characteristic } & \multirow{2}{*}{$\begin{array}{l}\text { Study population } \\
(\mathrm{N}=79083) \\
\mathrm{n}(\%)\end{array}$} & \multicolumn{2}{|c|}{ PCR-confirmed COVID-19 cases $(n=380)$} \\
\hline & & $\begin{array}{l}\text { Univariate analysis } \\
\mathrm{n}(\%) \mathrm{p} \text { value }\end{array}$ & Incidence rate \\
\hline \multicolumn{4}{|l|}{ Vaccination's history } \\
\hline $\begin{array}{l}\text { Influenza vaccine in prior } \\
\text { autumn }\end{array}$ & 22606 (28.6) & $205(53.9)<0.001$ & $906.8(787.1-1043.8)$ \\
\hline
\end{tabular}

$P$ values in univariate analysis were calculated by $\chi^{2}$, or Fisher's test as appropriate, comparing percentages in the study population versus COVID-19 cases; IR denotes incidence rates per 100000 persons-period (12 weeks); Cls denotes confidence intervals for incidence rates and were calculated assuming a Poisson distribution for uncommon events.

ACEls, ACE inhibitors; ARBs, angiotensin II receptor blockers; NSAIDs, non-steroidal anti-inflammatory drugs .

$\mathrm{p}<0.05$ (two-tailed). IBM SPSS Statistics for Windows V.24 (IBM Corp.) was used to analyse the data.

This methodology is very similar to the one reported in a previous article from the authors published in Journal of Clinical Hypertension (JCH). ${ }^{15}$ Both articles are part of the same project. Unlike the one published in JCH, the current article reports results referring to the total study population, distinguishing between community-dwelling and nursing-home residents and extends the analysis period until May 23.

\section{RESULTSE}

Across the study period, an amount of 2324 cohort members were PCR tested. Of them, 380 (16.4\%) presented a positive result (PCR-confirmed COVID-19) and $1944(83.6 \%)$ presented a negative result. Additionally, 377 cohort members with presumptive COVID-19 (clinical suspicion alone) were not PCR tested.

As compared with the structure of the study population (54\% aged $50-64$ years vs $46 \%$ aged $>=65$ years, $47.6 \%$ men vs $52.4 \%$ women, $98.2 \%$ community-dwelling vs $1.8 \%$ nursing-home residents), PCR testing was more frequently performed among elderly people and nursinghome residents. Indeed, PCR was tested (positive plus negative results) in 930 (40\%) people aged 50-64 years versus $1394(60 \%)$ in aged $>=65$ years $(\mathrm{p}<0.001), 1023$ $(44 \%)$ in men versus $1301(56 \%)$ in women $(\mathrm{p}=0.007)$ and $1789(77 \%)$ in community-dwelling versus $535(23 \%)$ in nursing-home residents $(\mathrm{p}<0.001)$.

Of the 380 PCR-confirmed COVID-19 cases, 158 $(41.6 \%)$ occurred in men and $222(58.4 \%)$ in women. By age groups, $101(26.6 \%)$ occurred in people aged $50-64$ years, $95(25 \%)$ in aged $65-79$ years and 184 $(48.4 \%)$ in 80 years or older. By residence, 160 cases $(42.1 \%)$ occurred in nursing-home residents and 220 $(57.9 \%)$ in community-dwelling individuals. This means an overall IR of 480.5 PCR-confirmed COVID-19 cases per 100000 persons-period (236.6 in 50-64years vs 365.2 in $65-79$ years vs 1771.6 in 80 years or older; 419.9 in men vs 535.5 in women)
The most prevalent pre-existing comorbidities/underlying conditions among the 380 patients with COVID-19 were hypertension (58.7\%), hypercholesterolaemia $(35 \%)$, chronic cardiac disease $(32.4 \%)$, diabetes $(26.8 \%)$ and obesity $(25.3 \%)$.

By underlying conditions, maximum IRs (per 100000 persons-period) emerged among those persons with neurological diseases (2848.5) followed by atrial fibrillation (1452.7), chronic renal failure (1094.7), chronic heart disease (915.5), chronic respiratory disease (866.3), diabetes (765.9), cancer (739.1) and hypertension (638.1). Lower IRs were observed among persons with rheumatic diseases (229.4) and smokers (211.8). According to pre-existing active medications, maximum IRs (per 100000) appeared among those receiving diuretics (1308.8), insulin (1282.1), oral anticoagulants (1175.9) and inhaled-respiratory therapy (969.3) (table 1).

Table 2 shows unadjusted and multivariable-adjusted analyses evaluating risk for suffering PCR-confirmed COVID-19 in the total study cohort. In the unadjusted analysis, many underlying conditions and medications use were associated with an increased risk. However, after multivariable adjustment, only age (HR 1.02; 95\% CI 1.01 to 1.03; $\mathrm{p}=0.002$ ), nursing-home residence (HR 21.83; 95\% CI 16.66 to $28.61 ; \mathrm{p}<0.001)$ and receiving diuretics (HR 1.35; 95\% CI 1.04 to 1.76 ; $\mathrm{p}=0.026$ ) appeared significantly associated with an increased risk. Conversely, smoking (HR 0.62; 95\% CI 0.41 to 0.93; $\mathrm{p}=0.022$ ), receiving ARBs (HR 0.68 ; $95 \%$ CI: 0.47 to $0.99 ; \mathrm{p}=0.046$ ) and antihistamines (HR 0.47; 95\% CI 0.22 to 1.01 ; $\mathrm{p}=0.052)$ appeared associated with a reduced risk.

Among community-dwelling individuals $(\mathrm{n}=77676)$, 1789 people were PCR tested. Of them, 1569 (87.7\%) presented a negative result and $220(12.3 \%)$ a positive result. Additionally, 358 people were codified as presumptive COVID-19 cases (clinical suspicion without PCR performed). Table 3 shows the distribution of PCR-confirmed COVID-19 cases and specific IRs by demographic characteristics, underlying conditions and 
Table 2 Cox regression analyses assessing unadjusted and adjusted risks to suffer PCR-confirmed COVID-19 in the total study cohort ( $\mathrm{N}=79083)$ : Tarragona region (Southern Catalonia, Spain) from 1st. March 2020 to 23rd. May 2020

\section{LC-COVID-19 cases ( $\mathrm{n}=349$ )}

\begin{tabular}{|c|c|c|}
\hline Characteristic & $\begin{array}{l}\text { Unadjusted } \\
\mathrm{HR}(95 \% \mathrm{Cl}) \mathrm{P} \text { value }\end{array}$ & $\begin{array}{l}\text { Adjusted } \\
\text { HR }(95 \% \mathrm{Cl}) \mathrm{P} \text { value }\end{array}$ \\
\hline \multicolumn{3}{|l|}{ Sociodemographic } \\
\hline Age (continuous years) & $1.07(1.07$ to 1.08$)<0.001$ & 1.02 (1.01 to 1.03$) 0.002$ \\
\hline Sex: women & 1.28 (1.04 to 1.57$) 0.019$ & 0.95 (0.76 to 1.18$) 0.624$ \\
\hline Nursing-home residence & 42.14 (34.37 to 51.66$)<0.001$ & 21.83 (16.66 to 28.61$)<0.001$ \\
\hline \multicolumn{3}{|l|}{ Comorbidities } \\
\hline Neurological disease & 7.03 (5.39 to 9.16$)<0.001$ & $1.31(0.97$ to 1.77$) 0.074$ \\
\hline Renal disease & $2.47(1.83$ to 3.34$)<0.001$ & $0.91(0.66$ to 1.26$) 0.556$ \\
\hline Cancer & 1.62 (1.20 to 2.19$) 0.002$ & 1.17 (0.86 to 1.60$) 0.315$ \\
\hline Rheumatic disease & $0.47(0.12$ to 1.90$) 0.293$ & 0.54 (0.13 to 2.19$) 0.386$ \\
\hline Respiratory disease & 1.97 (1.50 to 2.58$)<0.001$ & $1.29(0.89$ to 1.87$) 0.184$ \\
\hline Cardiac disease & $2.34(1.89$ to 2.90$)<0.001$ & 1.04 (0.80 to 1.34$) 0.790$ \\
\hline Atrial fibrillation & 3.38 (2.54 to 4.50$)<0.001$ & $1.17(0.74$ to 1.84$) 0.514$ \\
\hline Liver disease & $1.14(0.57$ to 2.30$) 0.712$ & $1.16(0.57$ to 2.35$) 0.684$ \\
\hline Diabetes & $1.81(1.45$ to 2.27$)<0.001$ & $1.10(0.73$ to 1.65$) 0.646$ \\
\hline Hypertension & $1.80(1.46$ to 2.20$)<0.001$ & $0.98(0.74$ to 1.29$) 0.869$ \\
\hline Hypercholesterolaemia & 1.02 (0.83 to 1.26$) 0.851$ & $0.88(0.70$ to 1.11$) 0.269$ \\
\hline Obesity & 0.89 (0.71 to 1.13$) 0.344$ & 0.87 (0.68 to 1.11$) 0.262$ \\
\hline Smoking & 0.40 (0.27 to 0.59$)<0.001$ & 0.62 (0.41 to 0.93$) 0.022$ \\
\hline \multicolumn{3}{|l|}{ Chronic medications use } \\
\hline Diuretics & 3.45 (2.76 to 4.30$)<0.001$ & 1.35 (1.04 to 1.76$) 0.026$ \\
\hline Beta blockers & 1.59 (1.22 to 2.06$) 0.001$ & $0.96(0.72$ to 1.29$) 0.790$ \\
\hline ACEls & 1.22 (0.96 to 1.54$) 0.098$ & 0.85 (0.65 to 1.13$) 0.260$ \\
\hline ARBs & 0.90 (0.65 to 1.26$) 0.552$ & 0.68 (0.47 to 0.99$) 0.046$ \\
\hline Calcium channel blockers & 1.77 (1.32 to 2.38$)<0.001$ & 1.31 (0.95 to 1.79$) 0.096$ \\
\hline Statins & 0.87 (0.67 to 1.12$) 0.276$ & $0.82(0.60$ to 1.11$) 0.200$ \\
\hline Oral anticoagulants & 2.65 (1.95 to 3.61$)<0.001$ & $1.26(0.76$ to 2.07$) 0.371$ \\
\hline Antiplatelet drugs & 2.24 (1.76 to 2.85$)<0.001$ & 1.35 (1.00 to 1.81$) 0.051$ \\
\hline Insulin & 2.87 (2.06 to 3.99$)<0.001$ & 1.47 (0.98 to 2.21$) 0.065$ \\
\hline Oral antidiabetic drugs & 1.44 (1.11 to 1.86$) 0.007$ & 1.05 (0.69 to 1.59 ) 0.823 \\
\hline Inhaled respiratory drugs & $2.22(1.69$ to 2.92$)<0.001$ & 1.24 (0.84 to 1.81$) 0.275$ \\
\hline Antineoplastic agents & 1.03 (0.51 to 2.08 ) 0.929 & 1.06 (0.51 to 2.20$) 0.876$ \\
\hline Systemic corticosteroids & 0.83 (0.34 to 2.00 ) 0.677 & 0.57 (0.23 to 1.40$) 0.218$ \\
\hline NSAIDs & $0.57(0.32$ to 1.00$) 0.051$ & 1.04 (0.58 to 1.87$) 0.901$ \\
\hline Antihistamines & 0.44 (0.21 to 0.92$) 0.029$ & $0.47(0.22$ to 1.01$) 0.052$ \\
\hline Proton-pump inhibitors & 2.04 (1.66 to 2.51$)<0.001$ & 0.93 (0.72 to 1.19$) 0.557$ \\
\hline Benzodiazepines & $1.72(1.36$ to 2.16$)<0.001$ & 1.25 (0.98 to 1.60$) 0.072$ \\
\hline \multicolumn{3}{|l|}{ Vaccination's history } \\
\hline Influenza vaccine in prior autumn & 2.93 (2.40 to 3.59$)<0.001$ & $1.02(0.79$ to 1.32$) 0.878$ \\
\hline Pneumococcal vaccination & $2.58(2.11$ to 3.16$)<0.001$ & $1.02(0.78$ to 1.33$) 0.904$ \\
\hline
\end{tabular}

HRs denotes hazard ratios and were calculated for those who had the condition as compared with those who had not the condition. In adjusted analysis, the HRs were adjusted for age (continuous years), sex, residence, comorbidities/underlying conditions and chronic medications use. Cls denotes confidence intervals.

ACEIs, ACE inhibitors; ARBs, angiotensin II receptor blockers; NSAIDs, non-steroidal anti-inflammatory drugs . 
Table 3 Incidence of PCR-confirmed COVID-19 cases according to baseline demographic and clinical characteristics (comorbidities/medications) in subgroup analysis restricted to community-dwelling individuals ( $n=77676)$ : Tarragona region (Southern Catalonia, Spain), March 1, 2020- May 23, 2020

\begin{tabular}{|c|c|c|c|}
\hline \multirow[b]{2}{*}{ Characteristic } & \multirow{2}{*}{$\begin{array}{l}\text { Study population } \\
(\mathrm{N}=77676) \\
\mathrm{n}(\%)\end{array}$} & \multicolumn{2}{|c|}{ PCR-confirmed COVID-19 cases $(n=220)$} \\
\hline & & $\begin{array}{l}\text { Univariate analysis } \\
n(\%) p \text { value }\end{array}$ & Incidence rate \\
\hline \multicolumn{4}{|l|}{ Sociodemographic } \\
\hline \multicolumn{4}{|l|}{ Age } \\
\hline 50-64 years & $42533(54.8)$ & $99(45.0)<0.001$ & $232.8(190.4-284.0)$ \\
\hline $65-79$ years & $25713(33.1)$ & $72(32.7)$ & $280.0(219.8-355.6)$ \\
\hline \multicolumn{4}{|l|}{ Sex } \\
\hline Men & $37145(47.8)$ & $108(49.1) 0.706$ & $290.8(237.8-354.7)$ \\
\hline Women & $40531(52.2)$ & $112(50.9)$ & $276.3(230.2-331.6)$ \\
\hline \multicolumn{4}{|l|}{ Comorbidities } \\
\hline Neurological disease & $1951(2.5)$ & $11(5.0) 0.018$ & $563.8(281.3-1009.2)$ \\
\hline Respiratory disease & $7075(9.1)$ & $47(21.4)<0.001$ & $664.3(484.3-890.2)$ \\
\hline Cardiac disease & $12925(16.6)$ & $68(30.9)<0.001$ & $526.1(413.0-668.2)$ \\
\hline Atrial fibrillation & $3561(4.6)$ & $26(11.8)<0.001$ & $730.1(476.8-1073.3)$ \\
\hline Liver disease & $1438(1.9)$ & $6(2.7) 0.334$ & $417.2(153.1-909.6)$ \\
\hline Diabetes & $12926(16.6)$ & $50(22.7) 0.015$ & $386.8(287.0-510.6)$ \\
\hline Hypertension & $33996(43.8)$ & $112(50.9) 0.032$ & 329.5 (274.4-395.3) \\
\hline Hypercholesterolaemia & 26766 (34.5) & 74 (33.6) 0.797 & $276.5(217.0-351.1)$ \\
\hline Obesity & $21344(27.5)$ & 57 (25.9) 0.602 & 267.1 (205.6-347.2) \\
\hline Smoking & $12640(16.3)$ & $19(8.6) 0.002$ & $150.3(90.5-234.5)$ \\
\hline Statins & $15911(20.5)$ & 47 (21.4) 0.746 & $295.4(215.3-395.8)$ \\
\hline Oral anticoagulants & $3741(4.8)$ & $27(12.3)<0.001$ & $721.7(475.6-1053.7)$ \\
\hline Antiplatelet drugs & $8810(11.3)$ & 40 (18.2) 0.001 & $454.0(324.2-617.5)$ \\
\hline Insulin & $2904(3.7)$ & $20(9.1)<0.001$ & $688.7(420.8-1060.6)$ \\
\hline Oral antidiabetic drugs & $10352(13.3)$ & 34 (15.5) 0.353 & 328.4 (228.9-456.5) \\
\hline Inhaled respiratory drugs & $6095(7.8)$ & $42(19.1)<0.001$ & 689.1 (492.0-937.2) \\
\hline Antineoplastic agents & $1581(2.0)$ & $2(0.9) 0.236$ & $126.5(15.3-456.7)$ \\
\hline Systemic corticosteroids & $1216(1.6)$ & 5 (2.3) 0.397 & $411.2(133.2-958.1)$ \\
\hline NSAIDs & $4305(5.5)$ & $12(5.5) 0.955$ & $278.7(144.1-487.8)$ \\
\hline Antihistamines & $3221(4.1)$ & $6(2.7) 0.290$ & $186.3(68.4-406.1)$ \\
\hline Proton-pump inhibitors & $17315(22.3)$ & $74(33.6)<0.001$ & $427.4(335.5-542.8)$ \\
\hline Benzodiazepines & $12654(16.3)$ & 49 (22.3) 0.016 & $387.2(287.3-511.1)$ \\
\hline \multicolumn{4}{|l|}{ Vaccination's history } \\
\hline Influenza vaccine in prior autumn & $21570(27.8)$ & 70 (31.8) 0.179 & $324.5(254.8-412.1)$ \\
\hline Pneumococcal vaccinated & $25224(32.5)$ & $100(45.5)<0.001$ & 396.4 (324.3-483.7) \\
\hline
\end{tabular}

$P$ values in univariate analysis were calculated by $\chi^{2}$, or Fisher's test as appropriate, comparing percentages in the study population versus COVID-19 cases; IR denotes incidence rates per 100000 persons-period (12 weeks); Cls denotes confidence intervals for incidence rates and were calculated assuming a Poisson distribution for uncommon events.

ACEIs, ACE inhibitors; ARBs, angiotensin II receptor blockers; NSAIDs, non-steroidal anti-inflammatory drugs 
Table 4 Cox regression analyses assessing unadjusted and adjusted risks to suffer PCR-confirmed COVID-19 among community-dwelling individuals ( $n=77676$ ): Tarragona region (Southern Catalonia, Spain), March 1, 2020- May 23, 2020

\begin{tabular}{|c|c|c|}
\hline \multirow[b]{2}{*}{ Characteristic } & \multicolumn{2}{|c|}{ LC-COVID-19 cases $(n=201)$} \\
\hline & $\begin{array}{l}\text { Unadjusted } \\
\mathrm{HR}(95 \% \mathrm{Cl}) \mathrm{p} \text { value }\end{array}$ & $\begin{array}{l}\text { Adjusted } \\
\text { HR }(95 \% \mathrm{Cl}) \mathrm{p} \text { value }\end{array}$ \\
\hline \multicolumn{3}{|l|}{ Sociodemographic } \\
\hline Age (continuous years) & $1.03(1.02$ to 1.04$)<0.001$ & 1.01 (0.99 to 1.02 ) 0.573 \\
\hline Sex: women & 0.95 (0.73 to 1.24) 0.708 & 0.97 (0.73 to 1.28$) 0.807$ \\
\hline \multicolumn{3}{|l|}{ Comorbidities } \\
\hline Neurological disease & 2.04 (1.12 to 3.75 ) 0.021 & 1.06 (0.56 to 2.01) 0.857 \\
\hline Renal disease & $2.32(1.54$ to 3.50$)<0.001$ & 1.22 (0.77 to 1.94$) 0.398$ \\
\hline Cancer & 1.88 (1.29 to 2.73 ) 0.001 & 1.52 (1.03 to 2.24$) 0.035$ \\
\hline Rheumatic disease & 0.41 (0.06 to 2.91) 0.371 & 0.41 (0.06 to 2.97) 0.375 \\
\hline Respiratory disease & $2.72(1.97$ to 3.75$)<0.001$ & 1.82 (1.08 to 3.07 ) 0.025 \\
\hline Cardiac disease & 2.24 (1.69 to 2.99$)<0.001$ & 1.53 (1.06 to 2.19$) 0.021$ \\
\hline Atrial fibrillation & $2.79(1.86$ to 4.21$)<0.001$ & 1.06 (0.48 to 2.33$) 0.882$ \\
\hline Liver disease & 1.49 (0.66 to 3.35) 0.336 & 1.24 (0.54 to 2.83$) 0.608$ \\
\hline Diabetes & 1.47 (1.08 to 2.02) 0.016 & 1.26 (0.70 to 2.28$) 0.441$ \\
\hline Hypertension & 1.33 (1.02 to 1.74$) 0.034$ & $1.06(0.72$ to 1.55$) 0.785$ \\
\hline Hypercholesterolaemia & 0.96 (0.73 to 1.28$) 0.798$ & 0.88 (0.64 to 1.20$) 0.405$ \\
\hline Obesity & 0.92 (0.68 to 1.25) 0.599 & 0.75 (0.54 to 1.03$) 0.076$ \\
\hline Smoking & 0.49 (0.30 to 0.78$) 0.003$ & $0.49(0.30$ to 0.80$) 0.004$ \\
\hline \multicolumn{3}{|l|}{ Chronic medications use } \\
\hline Diuretics & $2.62(1.92$ to 3.58$)<0.001$ & 1.54 (1.04 to 2.27$) 0.031$ \\
\hline Beta blockers & 1.63 (1.16 to 2.30$) 0.005$ & 1.02 (0.69 to 1.52$) 0.909$ \\
\hline ACEls & 0.88 (0.63 to 1.24) 0.462 & 0.66 (0.44 to 0.99$) 0.046$ \\
\hline ARBs & 1.20 (0.81 to 1.78 ) 0.356 & $0.75(0.47$ to 1.19$) 0.222$ \\
\hline Calcium channel blockers & 1.58 (1.06 to 2.36$) 0.026$ & 1.21 (0.78 to 1.87$) 0.395$ \\
\hline Statins & 1.05 (0.76 to 1.46$) 0.747$ & 0.72 (0.49 to 1.06$) 0.094$ \\
\hline Oral anticoagulants & $2.77(1.85$ to 4.14$)<0.001$ & 1.58 (0.71 to 3.48$) 0.261$ \\
\hline Antiplatelet drugs & 1.74 (1.23 to 2.45$) 0.002$ & 1.30 (0.84 to 2.02$) 0.243$ \\
\hline Insulin & $2.58(1.63$ to 4.08$)<0.001$ & 1.79 (1.00 to 3.21$) 0.059$ \\
\hline Oral antidiabetic drugs & 1.19 (0.82 to 1.71$) 0.356$ & 0.73 (0.40 to 1.32$) 0.295$ \\
\hline Inhaled respiratory drugs & $2.78(1.99$ to 3.89$)<0.001$ & 1.41 (0.81 to 2.45$) 0.225$ \\
\hline Antineoplastic agents & 0.44 (0.11 to 1.78$) 0.250$ & $0.36(0.09$ to 1.49$) 0.159$ \\
\hline Systemic corticosteroids & 1.46 (0.60 to 3.55$) 0.400$ & $1.03(0.41$ to 2.58$) 0.945$ \\
\hline NSAIDs & 0.99 (0.55 to 1.76) 0.959 & 1.17 (0.65 to 2.12$) 0.600$ \\
\hline Antihistamines & 0.65 (0.29 to 1.46) 0.294 & 0.51 (0.23 to 1.16$) 0.109$ \\
\hline Proton-pump inhibitors & $1.77(1.34$ to 2.34$)<0.001$ & $1.11(0.79$ to 1.57$) 0.555$ \\
\hline Benzodiazepines & 1.48 (1.07 to 2.03$) 0.017$ & $1.26(0.90$ to 1.76$) 0.186$ \\
\hline \multicolumn{3}{|l|}{ Vaccination's history } \\
\hline Influenza vaccine in prior autumn & 1.21 (0.91 to 1.61$) 0.182$ & 0.63 (0.44 to 0.91$) 0.012$ \\
\hline Pneumococcal vaccination & $1.73(1.33$ to 2.26$)<0.001$ & 1.29 (0.86 to 1.92$) 0.214$ \\
\hline
\end{tabular}

HRs denotes hazard ratios and were calculated for those who had the condition as compared with those who did not have the condition. In multivariable-adjusted analysis, HRs were adjusted for age (continuous years), sex, residence, comorbidities/underlying conditions and chronic medications use. Cls denote confidence intervals.

ACEls, ACE inhibitors; ARBs, angiotensin II receptor blockers; NSAIDs, non-steroidal anti-inflammatory drugs . 
Table 5 Univariate and multivariate analyses on laboratory-confirmed COVID-19 cases according to baseline demographic and clinical characteristics (comorbidities/medications) in subgroup analysis restricted to nursing-home residents ( $n=1407$ ): Tarragona region (Southern Catalonia, Spain) from 1st. March 2020 to 23rd. May 2020

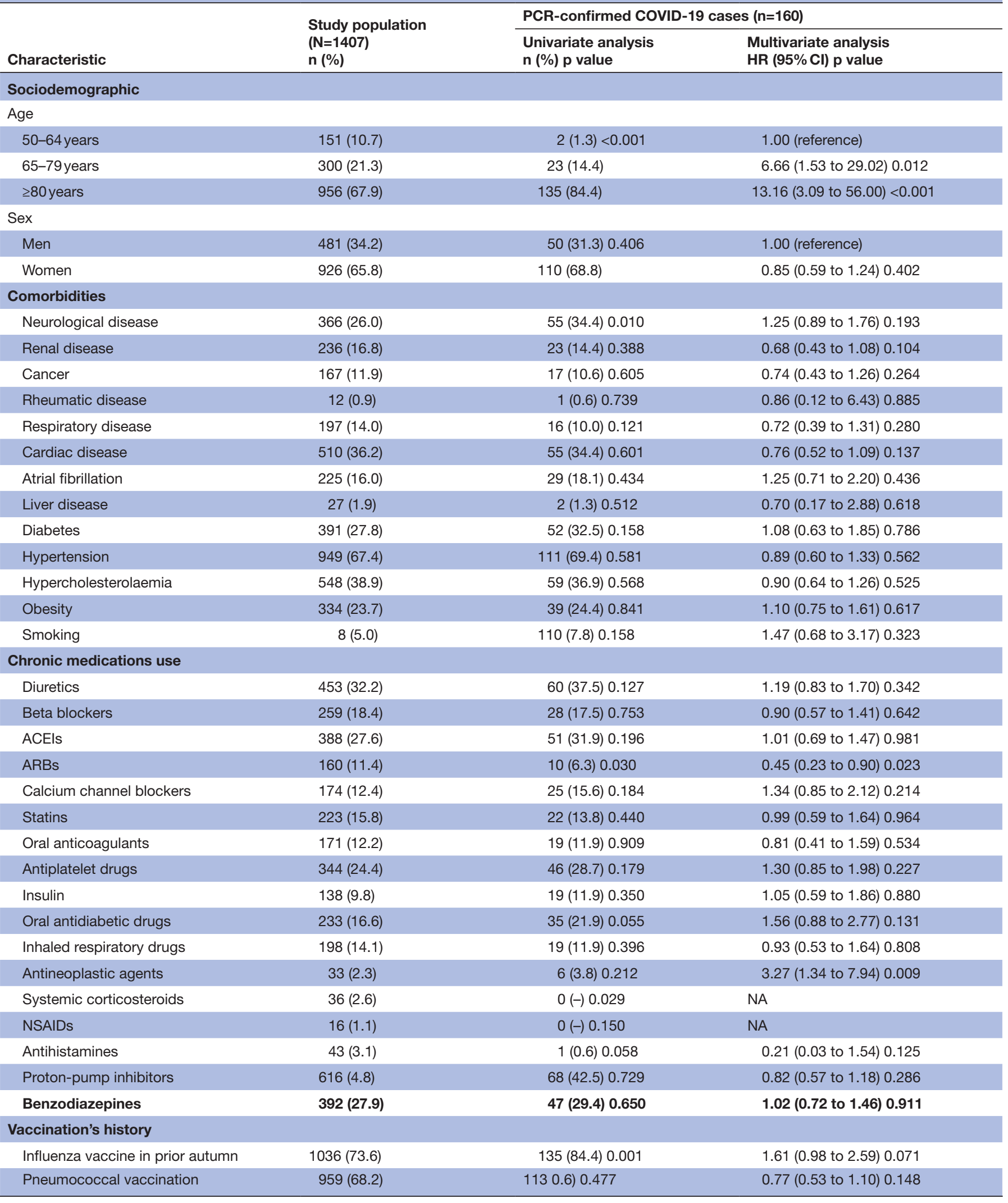




\begin{tabular}{|c|c|c|c|}
\hline \multirow[b]{2}{*}{ Characteristic } & \multirow{2}{*}{$\begin{array}{l}\text { Study population } \\
(\mathrm{N}=1407) \\
\mathrm{n}(\%)\end{array}$} & \multicolumn{2}{|c|}{ PCR-confirmed COVID-19 cases $(n=160)$} \\
\hline & & $\begin{array}{l}\text { Univariate analysis } \\
\mathrm{n}(\%) \mathrm{p} \text { value }\end{array}$ & $\begin{array}{l}\text { Multivariate analysis } \\
\text { HR }(95 \% \mathrm{Cl}) \mathrm{p} \text { value }\end{array}$ \\
\hline
\end{tabular}

$P$ values in univariate analysis were calculated by $\chi^{2}$ (or Fisher's test as appropriate) comparing percentages in the study population versus COVID-19 cases; HR denotes multivariable-adjusted hazard ratios (Cox regression) calculated for those who had the condition as compared with those who did not have the condition, being adjusted by age (continuous), sex, pre-existing comorbidities and medications use.

ACEIs, ACE inhibitors; ARBs, angiotensin II receptor blockers; NSAIDs, non-steroidal anti-inflammatory drugs.

medications use among community-dwelling individuals. In the multivariable analysis focused on these communitydwelling individuals, chronic respiratory disease (HR $1.82 ; 95 \%$ CI 1.08 to $3.07 ; \mathrm{p}=0.025$ ), cardiac disease (HR 1.53 ; $95 \%$ CI 1.06 to $2.19 ; \mathrm{p}=0.021$ ), cancer (HR 1.52; $95 \%$ CI 1.03 to $2.24 ; \mathrm{p}=0.035$ ), receiving diuretics (HR 1.54; $95 \%$ CI 1.04 to $2.27 ; \mathrm{p}=0.031$ ) and insulin (HR: 1.79 ; 95\% CI: 1.00 to $3.21 ; \mathrm{p}=0.049$ ) were associated with an increased risk, whereas smoking (HR 0.49; 95\% CI 0.30 to $0.80 ; \mathrm{p}=0.004$ ), receiving ACE inhibitors (HR 0.66; $95 \%$ CI 0.44 to $0.99 ; \mathrm{p}=0.046)$ and influenza vaccination in prior autumn (HR 0.63; 95\% CI 0.44 to $0.91 ; \mathrm{p}=0.012$ ) were associated with a decreased risk (table 4).

Among nursing-home residents $(\mathrm{n}=1407)$, where several outbreaks occurred, a total of 554 possible COVID-19 cases were observed. Of them, 375 were excluded by a PCR negative result, 160 were confirmed by positive PCR and 19 were not PCR tested. Table 5 shows univariate and multivariate analyses on PCR-confirmed COVID-19 cases in subgroup analysis restricted to nursing-home residents. In the multivariable analysis, increasing age and receiving antineoplastic agents were associated with an increased risk, whereas receiving ARBs was associated with a decreased risk (HR $0.45 ; 95 \%$ CI 0.23 to $0.90 ; \mathrm{p}=0.023$ ).

\section{DISCUSSION}

In the current context of COVID-19 clinical uncertainties, there is not clear evidence about possible clinical predisposing or protecting factors related to SARS-CoV-2 infection. In the present study, the overall incidence rate of PCR-confirmed COVID-19 (480.5 cases per 100000 persons-period) may be considered intermediate/low as compared with other Spanish regions. ${ }^{16}$

Considering sociodemographic variables, apart from nursing-home residence that increased more than 20 times the adjusted risk for PCR-confirmed COVID-19, we found that age increased by approximately $2 \%$ for each year the adjusted risk for suffering COVID-19. Despite COVID-19 being more frequent in women, sex did not alter significantly the risk of infection in multivariable analysis.

None comorbidity appeared to be independently associated with a significant increased risk for PCR-confirmed COVID-19 in the multivariable analysis evaluating the total study population. Nevertheless, pre-existing cancer, chronic respiratory disease and cardiac disease emerged to be significantly associated with an increased risk in subgroup analysis focused on community-dwelling individuals. Hypertension, diabetes and/or obesity did not emerge to be independently associated with a significant increased risk for suffering COVID-19 in our adjusted analyses. There is general consensus considering these conditions as major risk conditions related to poor prognosis in hospitalised patients with COVID-19, ${ }^{1-4} 7$ 76-20 $^{\text {but }}$ there is lacking data assessing the role of these conditions to predispose for suffering infection. ${ }^{216}$

Surprisingly, smoking was associated with a statistically significant decreased risk for suffering COVID-19 in both multivariable analyses assessing the total study cohort and the subgroup of community-dwelling individuals. This surprising data is not unique ${ }^{521}$ and merits further investigations. Opposite findings about poor prognosis among smokers with COVID-19 have been reported. ${ }^{2} 1622$ Obviously, it must not be forgotten that smoking has severe pathological consequences (being a serious danger for health) and nicotine is a drug responsible for smoking addiction. Nevertheless, as it has been hypothesised elsewhere, ${ }^{23}$ a potential protective role for nicotinic agents (under controlled conditions) against COVID-19 infection should be explored.

While angiotensin receptors have been related to the physiopathological mechanisms of SARS-CoV-2 infection, ${ }^{24}{ }^{25}$ receiving ACEIs/ARBs emerged associated with a reduced risk in this study. Since the beginning of the COVID-19 global pandemic, concerns have been raised about the possibility that receiving ACEIs/ARBs could predispose individuals to severe COVID-19. ${ }^{26} 27$ These concerns were based on the fact that ACE2 receptors facilitates SARS-CoV-2 cell invasion. This negative effect was previously established during other earlier SARS-CoV outbreaks. ${ }^{24-27}$ Most recent studies have concluded that there is no clinical or experimental evidence supporting that ACEIs or ARBs augment the susceptibility to SARS-CoV-2 or aggravate the severity and outcomes of COVID-19 at present. ${ }^{28-31}$ Conversely, ACEIs and ARBs may be associated with lower incidence and/or improved outcome in patients with lower respiratory tract infections, ${ }^{32}$ and lower risk of all-cause mortality among hospitalised patients with COVID-19. ${ }^{33}$ Our findings are in accordance with the above mentioned findings and supports that the use of RAAS inhibitors could be beneficial in reducing risk for COVID-19 infection.

Other cardiovascular medications (ie, statins, antiplatelet and/or oral anticoagulant drugs) used before COVID-19 exposition did not significantly alter the risk for COVID-19 
in the present study. The use of anticoagulant therapy has been proposed to reduce risk of thrombotic events during and after COVID-19, but studies analysing the influence of the use of these drugs before infection are scarce and mostly focused on interactions with antiviral therapy. ${ }^{34}$ Considering specifically statins, it has been reported that adjuvant treatment and continuation of pre-existing statin therapy could improve the clinical course of patients with COVID-19, either by their immunomodulatory action or by preventing cardiovascular damage. ${ }^{35}$

Receiving NSAIDs or corticosteroids (which have been associated with good outcomes when using in patients with severe COVID-19) ${ }^{36}$ did not significantly alter risk for suffering infection in our study cohort. A pre-print study has reported that prior use of oral steroid medications was associated with decreased COVID-19 positive testing risk, but increased inpatient admission risk. ${ }^{6}$ Available publications recommend caution until further evidence emerges surrounding the use of these drugs in COVID-19 patients. ${ }^{37}$

Considering controversy about chloroquine/hydroxychloroquine use, ${ }^{38}$ none COVID-19 case was observed among 168 people receiving this drug (because systemic rheumatoid disease), but this study has lack statistical power to assess it.

Antihistamine use was associated with an almost statistically significant reduction risk of COVID-19 in the total study cohort, which would require further investigation. At present, there is no clear evidence that currently available antihistamines increase or decrease the risk of severe COVID-19 disease f. Of note, H1 receptors are expressed on the surface of the smooth musculature of the respiratory tract, neutrophils, eosinophil, macrophages, monocytes and $\mathrm{T}$ and $\mathrm{B}$ lymphocytes; however, it is not evaluated what the clinical significance of the effect of these drugs may be at this level. ${ }^{39}$ Considering H2, famotidine use has been associated with improved clinical outcomes in hospitalised patients with COVID-19. ${ }^{40}$

Community-dwelling individuals who received influenza vaccination in prior autumn appeared to be at decreased risk of suffering PCR-confirmed COVID-19 in our adjusted analysis. Although this finding may be possibly related to residual confounding due to unmeasured factors (eg, lifestyle or healthcare-related factors), it merits further investigations exploring a possible immunity-related mechanism explanation (which could be important for future prevention strategies). In this way, it has been hypothesised that the resultant immunity against prior influenza infection or vaccination would, at least in part, foster immunity against SARS-CoV-2 because of cross reactivity of immunity between influenza and coronavirus (due to similarities in their structures). ${ }^{41}$

Major strengths in this study were its population-based design (a large cohort involving more than 79000 people) and the use of multivariable analysis methods to estimate accurately possible relationships between suffering COVID-19 and common chronic medical conditions and medications use among middle aged and older adults (who suffer the greatest burden of severe disease). The study has also several limitations, mainly related to its observational nature and retrospective design. Assessing COVID19 , the most specific outcome is a laboratory-confirmed by PCR testing infection. However, this outcome depends on the reliability of RT-PCR performed (ie, quality of the nasopharyngeal swabs specimen, timing of collection, sensitivity of tests used) and guidelines for testing over study period. On this concern, the availability of PCR tests was scarce at the beginning of the epidemic period in our setting and they were not routinely performed for all presumptive cases, being PCR tests prioritised for hospitalised or patients with severe case. Obviously, residual confounding in incidence and risk estimates related to selection bias may not be excluded considering that PCR testing was not uniformly performed.

Of note, most COVID-19 cases included in this study were those who were severe enough to warrant medical attention during the epidemic period. Thus, it must be highlighted that those cohort members who were asymptomatic but SARS-CoV-2 infected, those that were oligosymptomatic and those that had mild symptoms (who mostly were in self-isolation and self-medicating in accordance with the recommendations of the health authorities at the time) were largely underestimated in the present study.

We did subgroup analysis (community-dwelling/nursinghome) and multivariable adjustments but, as all observational studies, a residual confounding due to unmeasured factors (eg, epidemiological, social, job and/or health carerelated factors) may not be completely excluded. We have not data about need for hospitalisation and clinical course (hospitalisation/intensive care unit admission or death) and, consequently, the study was not able to assess severity degree of cases. Despite the large size of the study cohort, there were relatively few events $(n=380)$ that limits the statistical power, especially in the subgroup analysis. The study was conducted in a single geographical area and, logically, specific incidence data may not be directly extrapolated to other geographical regions with distinct epidemic conditions. Nevertheless, adjusted-risk estimates may be helpful to better characterise risk profile for suffering COVID-19 among middle-aged and older adults in relation with common chronic medications use, providing new arguments to explore possible preventive/treatment research lines.

In summary, our data support that increasing age, nursing-home residence, pre-existing cancer, chronic respiratory and cardiac disease are independent major predisposing conditions to suffer COVID-19 among middle-aged and older adults. Patients receiving diuretics were also at increased risk. Conversely, smokers (who suffered the lowest incidence), patients receiving RAAS inhibitors (and possibly antihistamines) and those community-dwelling individuals that received influenza vaccination in prior autumn appear at decreased risk, which should be closely investigated in future studies specifically focused on these concerns. We note that for most common chronic medications/treatments there is lacking data reporting the possible influence of previous 
use of these medications on the risk for developing COVID-19.

On a clinical and public health-oriented point of view, meanwhile an efficacious treatment or vaccination against COVID-19 will be available; universal influenza vaccination, RAAS inhibitors in cardiovascular patients and possibly antihistamine drugs in patients with allergies could be complementary tools partially protecting against COVID-19.

\section{Author affiliations}

${ }^{1}$ Primary Healthcare Service Camp de Tarragona, Institut Catala de la Salut (ICS), Tarragona, Catalunya, Spain

${ }^{2}$ Unitat de Suport a la recerca Camp de Tarragona-Reus, IDIAP Jordi Gol, Barcelona, Catalunya, Spain

${ }^{3}$ Information and Communication Technologies, Institut Catala de la Salut (ICS), Tarragona, Catalunya, Spain

${ }^{4}$ Department of Microbiology, Hospital Universtari Joan XXIII, Institut Catala de la Salut (ICS), Tarragona, Catalunya, Spain

${ }^{5}$ Department of Pharmacology, Primary Healthcare Service Camp de Tarragona, Institut Catala de la Salut (ICS), Tarragona, Catalunya, Spain

${ }^{6}$ Direction, IDIAP Jordi Gol, Barcelona, Catalunya, Spain

Contributors AVC designed the study and wrote the manuscript; CTF and FGB obtained data; ESG, IHG and CDC assessed outcomes; $00 \mathrm{G}$ and AVR did statistical analyses; FBR revised pharmacological data; AVC and JBG coordinated the study.

Funding This study is supported by a grant from the Instituto de Salud Carlos III of the Spanish Health Ministry (file COV20/00852; call for the SARS-CoV-2/COVID-19 disease, RDL 8/2020, 17 March 2020). The funders had no role in study design, data collection and analysis, decision to publish or preparation of the manuscript.

Competing interests None declared.

Patient consent for publication Not required.

Ethics approval The study was approved by the ethical committee of the Institution (Ethics Committee IDIAP Jordi Gol, Barcelona, file 20/065-PCV) and was conducted according to the Helsinki Declaration and Spanish legislation on biomedical studies, data protection and respect for human rights.

Provenance and peer review Not commissioned; externally peer reviewed.

Data availability statement Data are available upon reasonable request.

Supplemental material This content has been supplied by the author(s). It has not been vetted by BMJ Publishing Group Limited (BMJ) and may not have been peer-reviewed. Any opinions or recommendations discussed are solely those of the author(s) and are not endorsed by BMJ. BMJ disclaims all liability and responsibility arising from any reliance placed on the content. Where the content includes any translated material, BMJ does not warrant the accuracy and reliability of the translations (including but not limited to local regulations, clinical guidelines, terminology, drug names and drug dosages), and is not responsible for any error and/or omissions arising from translation and adaptation or otherwise.

Open access This is an open access article distributed in accordance with the Creative Commons Attribution Non Commercial (CC BY-NC 4.0) license, which permits others to distribute, remix, adapt, build upon this work non-commercially, and license their derivative works on different terms, provided the original work is properly cited, appropriate credit is given, any changes made indicated, and the use is non-commercial. See: http://creativecommons.org/licenses/by-nc/4.0/.

\section{ORCID iD}

Eva M. Satué-Gracia http://orcid.org/0000-0003-1559-6778

\section{REFERENCES}

1 Yang J, Zheng Y, Gou X, et al. Prevalence of comorbidities and its effects in patients infected with SARS-CoV-2: a systematic review and meta-analysis. Int J Infect Dis 2020;94:91-5.

2 Liang W-H, Guan W-J, Li C-C, et al. Clinical characteristics and outcomes of hospitalised patients with COVID-19 treated in Hubei (epicentre) and outside Hubei (non-epicentre): a nationwide analysis of China. Eur Respir J 2020;55:2000562.
3 Grasselli G, Zangrillo A, Zanella A, et al. Baseline characteristics and outcomes of 1591 patients infected with SARS-CoV-2 admitted to ICUs of the Lombardy region, Italy. JAMA 2020;323:1574-81.

4 Zhou F, Yu T, Du R, et al. Clinical course and risk factors for mortality of adult inpatients with COVID-19 in Wuhan, China: a retrospective cohort study. Lancet 2020;395:1054-62.

5 de Lusignan S, Dorward J, Correa A, et al. Risk factors for SARS-CoV-2 among patients in the Oxford Royal College of general practitioners research and surveillance centre primary care network: a cross-sectional study. Lancet Infect Dis 2020;20:1034-42.

6 Chang TS, Ding Y, Freund MK, et al. Prior diagnoses and medications as risk factors for COVID-19 in a Los Angeles health system. Preprint. medRxiv 2020.

7 Ssentongo P, Ssentongo AE, Heilbrunn ES, et al. Association of cardiovascular disease and 10 other pre-existing comorbidities with COVID-19 mortality: a systematic review and meta-analysis. PLOS One 2020;15:e0238215.

8 Vahidy FS, Nicolas JC, Meeks JR, et al. Racial and ethnic disparities in SARS-CoV-2 pandemic: analysis of a COVID-19 observational Registry for a diverse US metropolitan population. BMJ Open 2020;10:e039849.

9 IDESCAT. Statistical Institute of Catalonia. Available: https://www. idescat.cat/?lang=en [Accessed 2 Oct 2020].

10 World Medical Association. Wma Declaration of Helsinki - ethical principles for medical research involving human subjects. Available: https://www.wma.net/policies-post/wmadeclaration-of-helsinkiethical-principles-for-medical-research-involving-human-subjects/ [Accessed 14 May 2020].

11 Vila-Corcoles A, Hospital-Guardiola I, Ochoa-Gondar O, et al. Rationale and design of the CAPAMIS study: effectiveness of pneumococcal vaccination against community-acquired pneumonia, acute myocardial infarction and stroke. BMC Public Health 2010;10:25.

12 Generalitat de Catalunya. Sub-direcció General de Vigil ncia i Resposta a Emergències de Salut Pública. Procediment d'actuació enfront de casos d'infecció pel nou coronavirus SARSCoV-2. Available: https://canalsalut.gencat.cat/web/.content/_A-Z/C/ coronavirus-2019-ncov/material-divulgatiu/procediment-actuaciocoronavirus.pdf [Accessed 16 May 2020].

13 Lieberman JA, Pepper G, Naccache SN, et al. Comparison of Commercially Available and Laboratory-Developed Assays for In Vitro Detection of SARS-CoV-2 in Clinical Laboratories. J Clin Microbiol 2020;58. doi:10.1128/JCM.00821-20. [Epub ahead of print: 23 Jul 2020].

14 WHO Collaborating Centre for Drug Statistics Methodology. ATC/ DDD index 2020, 2020. Available: https://www.whocc.no/atc_ddd index/ [Accessed 12 May 2020].

15 Vila-Corcoles A, Satue-Gracia E, Ochoa-Gondar O, et al. Use of distinct anti-hypertensive drugs and risk for COVID-19 among hypertensive people: a population-based cohort study in southern Catalonia, Spain. J Clin Hypertens 2020;22:1379-88.

16 Gobierno de España, Secretaría General de Sanidad y Consumo, Dirección General de Salud Pública, Calidad e innovación, Centro de Coordinación de Alertas y Emergencias Sanitarias. Información científica-técnica. Enfermedad por coronavirus, COVID19. Available: https://www.mscbs.gob.es/profesionales/saludPublica/ccayes/ alertasActual/nCov/documentos/20200417_ITCoronavirus.pdf [Accessed 5 May 2020].

17 Deng G, Yin M, Chen X, et al. Clinical determinants for fatality of 44,672 patients with COVID-19. Crit Care 2020;24:179.

18 Guzik TJ, Mohiddin SA, Dimarco A, et al. COVID-19 and the cardiovascular system: implications for risk assessment, diagnosis, and treatment options. Cardiovasc Res 2020;116:1666-87.

19 Cook TM. The importance of hypertension as a risk factor for severe illness and mortality in COVID-19. Anaesthesia 2020;75:976-7.

20 Sattar N, Mclnnes IB, McMurray JJV. Obesity is a risk factor for severe COVID-19 infection: multiple potential mechanisms. Circulation 2020;142:4-6.

21 Miyara M, Tubach F, Pourcher V, et al. Low incidence of daily active tobacco smoking in patients with symptomatic COVID-19. Qeios https://www.qeios.com/read/WPP19w.3

22 Lippi G, Henry BM. Active smoking is not associated with severity of coronavirus disease 2019 (COVID-19). Eur J Intern Med 2020;75:107-8.

23 Changeux J-P, Amoura Z, Rey FA, et al. A nicotinic hypothesis for Covid-19 with preventive and therapeutic implications. C R Biol 2020;343:33-9.

24 Wan Y, Shang J, Graham R, et al. Receptor recognition by the novel coronavirus from Wuhan: an analysis based on decade-long structural studies of SARS coronavirus. J Virol 2020;94:e00127-20. 
25 Yan R, Zhang Y, Li Y, et al. Structural basis for the recognition of SARS-CoV-2 by full-length human ACE2. Science 2020;367:1444-8.

26 Esler M, Esler D. Can angiotensin receptor-blocking drugs perhaps be harmful in the COVID-19 pandemic? J Hypertens 2020;38:781-2.

27 Versmissen J, Verdonk K, Lafeber M, et al. Angiotensin-Converting enzyme-2 in SARS-CoV-2 infection: good or bad? J Hypertens 2020;38:1196-7.

28 de Abajo FJ, Rodríguez-Martín S, Lerma V, et al. Use of reninangiotensin-aldosterone system inhibitors and risk of COVID-19 requiring admission to hospital: a case-population study. Lancet 2020;395:1705-14.

29 Reynolds HR, Adhikari S, Pulgarin C, et al. Renin-AngiotensinAldosterone system inhibitors and risk of Covid-19. N Engl J Med 2020;382:2441-8.

30 Kai H, Kai M. Interactions of coronaviruses with ACE2, angiotensin II, and RAS inhibitors-lessons from available evidence and insights into COVID-19. Hypertens Res 2020;43:648-54.

31 Meng J, Xiao G, Zhang J, et al. Renin-Angiotensin system inhibitors improve the clinical outcomes of COVID-19 patients with hypertension. Emerg Microbes Infect 2020;9:757-60.

32 Kreutz R, Algharably EAE-H, Azizi M, et al. Hypertension, the renin-angiotensin system, and the risk of lower respiratory tract infections and lung injury: implications for COVID-19. Cardiovasc Res 2020;116:1688-99.

33 Zhang P, Zhu L, Cai J, et al. Association of inpatient use of angiotensin-converting enzyme inhibitors and angiotensin II receptor blockers with mortality among patients with hypertension hospitalized with COVID-19. Circ Res 2020;126:1671-81.
34 Testa S, Prandoni P, Paoletti O, et al. Direct oral anticoagulant plasma levels' striking increase in severe COVID-19 respiratory syndrome patients treated with antiviral agents: the Cremona experience. $J$ Thromb Haemost 2020;18:1320-3.

35 Castiglione V, Chiriacò M, Emdin M, et al. Statin therapy in COVID-19 infection. Eur Heart J Cardiovasc Pharmacother 2020;6:258-9.

36 Wang $\mathrm{Y}$, Jiang $\mathrm{W}, \mathrm{He} \mathrm{Q}$, et al. Early, low-dose and short-term application of corticosteroid treatment in patients with severe COVID-19 pneumonia: single-center experience from Wuhan, China. medRxiv.

37 Russell B, Moss C, Rigg A, et al. COVID-19 and treatment with NSAIDs and corticosteroids: should we be limiting their use in the clinical setting? Ecancermedicalscience 2020;14:1023.

38 Hernandez AV, Roman YM, Pasupuleti V, et al. Hydroxychloroquine or chloroquine for treatment or prophylaxis of COVID-19: a living systematic review. Ann Intern Med 2020;173:287-96.

39 Simons FER, Simons KJ. Histamine and $\mathrm{H} 1$-antihistamines: celebrating a century of progress. J Allergy Clin Immunol 2011;128:1139-50.

40 Freedberg DE, Conigliaro J, Wang TC, et al. Famotidine use is associated with improved clinical outcomes in hospitalized COVID-19 patients: a propensity score matched retrospective cohort study. Gastroenterology 2020;159:1129-31.

41 Salem ML, El-Hennawy D. The possible beneficial adjuvant effect of influenza vaccine to minimize the severity of COVID-19. Med Hypotheses 2020;140:109752. 